\title{
Evaluation of the Environmental Impact Assessment System in Bahrain
}

\author{
Humood A. Naser \\ Department of Biology, College of Science, University of Bahrain, Sakhir, Kingdom of Bahrain. \\ Email: hnaser@sci.uob.bh
}

Received December $17^{\text {th }}$, 2011; revised January $12^{\text {th }}$, 2012; accepted February $7^{\text {th }}, 2012$

\begin{abstract}
Environmental Impact Assessment (EIA) was formally adopted as a measure to protect the environment in Bahrain in 1998. A decade after its implementation, this paper evaluates the current EIA system in Bahrain using a set of criteria. The evaluation was based on review of literature, investigation of legislative and administrative framework and interviews with EIA practitioners. Several measures are required to further strengthen the EIA system in Bahrain including amending EIA laws to include whole aspects of EIA process, developing comprehensive guidelines on procedural EIA, increasing public participation, improving capacity building and integrating environmental concerns to higher-level policy making through existing national environmental strategies. Findings of this study could contribute to wider international experience of EIA performance in developing countries.
\end{abstract}

Keywords: Environmental Impact Assessment; Bahrain; Arabian Gulf

\section{Introduction}

Environmental Impact Assessment (EIA) is considered a standard tool for decision-making in most countries throughout the world [1]. EIA aims at integrating environmental considerations in the decision-making system, minimizing or avoiding adverse impacts, protecting natural systems and their ecological processes, and implementing principles of sustainable development [2]. Therefore, an effective EIA is reflected in a better decisionmaking, improved environmental protection, and achievement in sustainable development [3].

Recognizing the role of EIA in protecting environment from degradation and pollution associated with economic developments, many developing countries have developed EIA legislations [4]. Variations in EIA effectiveness and performance in developing countries have widely been reported and attributed to weaknesses in legal regulations, administrative procedures, impact prediction approaches, and decision-making processes [5-11].

Unlike several developing countries, oil economies have enabled accelerated developments in Arabian Gulf countries. These developments are often associated with environmental degradation. While early EIA systems in several developing countries were introduced due to the requirements of donor institutions [12], EIA systems in the Arabian Gulf countries were nationally adopted to protect the environment from the rapid urbanization and industrialization [13].
Investigating the strengths and weaknesses of any EIA system is a fundamental step in order to examine the likely opportunities to improve the performance and effectiveness of that system [11]. Despite rapid urbanization and economic development that may be associated with environmental impacts in the Arabian Gulf countries including Bahrain, studies investigating performance of EIA have been limited.

Bahrain formally adopted EIA in its environmental system in 1998 to protect the environment and to reduce environmental degradation associated with major developmental projects. A decade after its implementation, this paper aims to evaluate the effectiveness of the existing EIA system in Bahrain, as a case study from the Arabian Gulf countries. Findings of this study could contribute to wider international experience of EIA performance in developing countries.

\section{Methodology}

Criteria to evaluate the performance and effectiveness of the Bahraini EIA system were primarily adopted from Wood [14]. These criteria have been frequently used to evaluate EIA systems in developing and transitional countries $[5,6,9,11,15]$. The criteria are descriptively orientated and can be divided into two conceptual models; systematic and foundation measures [16]. Systemic measures are features of EIA designed to deliver quality assurance in practice and administration of EIA including 
both legislative and administrative framework as well as aspects of EIA process such as screening, scoping, alternatives, public participation, review of EIA reports, mitigation and monitoring. Foundation measures are actions undertaken to improve the effectiveness of EIA system including the existence of EIA guidelines, training, capacity building and professional recognition (Table 1).

Several sources of data and information were utilized to conduct the evaluation of EIA system in Bahrain. Available published and gray literatures related to environmental system in Bahrain were reviewed. EIA related documents and guidelines were investigated. However, these documents including EIA reports are typically out of the public domain. EIA legislations in Bahrain were analyzed. Opinions of professionals and practitioners involved in EIA process were solicited to ascertain the range of views held on the effectiveness of EIA in Bahrain. A survey based on the evaluation criteria was performed by both interviews and sending emails during July and August 2011. The approached and contacted EIA practitioners represent the environmental authority, environmental consultant firms, academic and research institutions and environmental societies. A total of twenty EIA practitioners were interviewed and contacted, which is considered a sufficient sample size in a small country like Bahrain.

\section{EIA Systemic Measures}

\subsection{Legislative Framework of EIA in Bahrain}

The initial attempt to incorporate environmental concerns into major industrial projects in Bahrain can be traced back to 1992. The Environmental Protection Committee (EPC), at that time, started to environmentally evaluate certain industrial projects based on a Memorandum of Understanding between the EPC and the Ministry of Development and Industry [17].

Legislative Decree No. 21 of 1996 with respect to the Environment requires the adoption of plans and policies using appropriate procedures to prevent and combat the deterioration of the environment. EIA was defined in Article 2 of this Decree as a measure to protect the environment. Additionally, Articles 20, 21, 22 and 24 relate the approval of any project by the environmental authority to its potential impacts on the environment, and ensure that existing projects are adopting mitigation measures to prevent adverse impacts.

Although EIA was recognized in the general environmental law, it only became mandatory in 1998. EIA was formally introduced as a tool to bring environmental concerns into the Bahraini decision making process in a systematic way through the Ministerial Order No. 1 of 1998 with respect to Environmental Evaluation for Projects. According to this Order, two types of projects are sub-
Table 1. Summary of the evaluation criteria for EIA system in Bahrain [14].

\begin{tabular}{l}
\hline Systemic measures \\
\hline 1. EIA legislation \\
1.1. Legal framework of EIA \\
1.2. Appeal by the developer and public against decisions \\
1.3. Legal specification of time limits \\
1.4. Formal framework for Strategic environmental assessment \\
(SEA) \\
2. EIA administration \\
2.1. Competent authority for EIA \\
2.2. Review body for EIA
\end{tabular}

2.3. Level of coordination with other planning and pollution control bodies

3. EIA process

3.1. Specified screening categories

3.2. Systemic screening approach

3.3. Systemic scoping approach

3.4. Requirement to consider alternatives

3.5. Specified EIA report content

3.6. Systemic EIA report review approach

3.7. Public participation in EIA process

3.8. Systemic decision-making approach

3.9. Requirement for environmental management plans

3.10. Requirement for mitigation of impacts

3.11. Requirement for impact monitoring

3.12. Experience of SEA

Foundation measures

4. Measures to improve EIA effectiveness

4.1. Existence of guidelines

4.2. Expertise in conducting EIA

4.3. Training and capacity-building

jected to EIA; public and specific. The public projects are related to infrastructure developments such as ports, airports, roads and new towns. Specific projects are those with capacity to cause changes in the quality of the environment. A list of 30 projects and activities was accompanied with the Order. The Order requires that project proponents of these projects should submit information and project details based on various types of screening forms in order to determine the need for full EIA. The project proponents are required to submit an EIA report that conducted by an approved consulting firm. The elements and factors required to be covered in the EIA report are mentioned only in Articles 8 and 9 of the Order.

The Order specifies 60 days as the timescale of reviewing the EIA reports by the competent authority. Although the Order allows for appeal by project proponent 
against the decision of the competent authority by forming a committee from concerned bodies to resolve the issue, no such case has ever been reported.

Similar to EIA legislations in countries of the Middle East and North Africa [6], and most of transitional and developing countries [18,19], this Bahraini Order suffers from several shortcomings that can constrain the effectiveness of EIA process. The Order neglects the role of public participation or involvement of stakeholders in the EIA process, fails to address cumulative impacts, project alternatives, capacity building and public awareness, and lacks provisions for Strategic Environmental Assessment (SEA). Comprehensive EIA legislations are fundamentals for an effective EIA process [9]. Although this Order has enabled EIA legislation in Bahrain, $60 \%$ of the EIA practitioners interviewed agreed that a more comprehensive law that details the principles and procedures of EIA is required.

\subsection{Administrative Procedure of EIA in Bahrain}

The EPC established by Decree No. 7 of 1980 under the Ministry of Health, was the first governmental authority concerned with the protection of the Bahraini environment. The EPC was upgraded by the Legislative Decree No. 21 of 1996, establishing 'Environmental Affairs' under the Ministry of Housing, Municipalities, and Environment, which was reorganized under the Ministry of State for the Municipalities Affairs and Environmental Affairs in 2000. A second governmental body concerned with wildlife protection is the National Committee for Wildlife Protection, which was established by the Legislative Decree No. 2 of 1995. This committee was upgraded to become the National Commission for Wildlife Protection by the Legislative Decree No. 12 of 2000. The Directorate of Fisheries is another governmental sector concerned with the management of marine resources in Bahrain.

For the purpose of integrating efforts and resources to achieve effective protection of the environment, the three main governmental bodies concerned with the environment were joined under the umbrella of the "Public Commission for the Protection of Marine Resources, Environment and Wildlife" (PCPMREW) in 2002. The PCPMREW was established by the Legislative Decree No. 50 of 2002 and reorganized further by Decrees No. 10 and No. 43 of 2005.

Ministerial Order No. 1 of 1998 with respect to Environmental Evaluation for Projects identifies "Environmental Affairs" as the competent authority responsible for environmentally licensing projects and developments. The Directorate of Environmental Assessment and Planning (DEAP) at the General Directorate for the Protection of Wildlife and Environment (GDPWE) is responsi- ble for screening, scoping, revision and evaluation of EIA studies before proposed projects are given approval. EIA effectiveness is restricted in some developing countries due to the overlapping roles of several concerned governmental bodies [6]. Around $45 \%$ of the EIA practitioners interviewed stressed PCPMREW as a positive initiative towards the institutionalization of the authorities concerned with the environment in Bahrain. However, planning and implementation of major projects are carried out in a sectoral manner according to the mandate of each ministry or governmental body [20]. Around $80 \%$ of the EIA practitioners interviewed agreed that most of projects are in their late stages of planning and implementation when seeking environmental authorization from the PCPMREW, which could restrict the effectiveness of EIA process.

\subsection{EIA Process in Bahrain}

\subsubsection{Screening}

Screening process narrows the application of EIA to projects with potentially significant impacts. In Bahrain, screening approaches include list-based screening by comparing projects against the mandatory list of 30 projects and activities that require full EIA, or case-by-case screening through screening forms. These forms include a description of the project, its location, and the duration of implementation as well as its likely impacts on the environment. Currently, there are nine screening forms produced by DEAP concerning infrastructure projects, industrial projects, petrol filling stations, reclamation and dredging operations, and service projects. However, these forms lack guidelines, criteria and thresholds for screening such as project scale, cumulative impacts, and the sensitivity of proposed site, which could potentially cause variation in the interpretation of the need for full EIA [1].

For the purpose of minimizing the chance of projects with significant impacts of being exempted, $60 \%$ of the EIA practitioners interviewed stressed the need to revise and update both the list of mandatory projects and the screening forms. Additionally, a hybrid approach of screening involving both the use of project lists accompanied with thresholds and the case-by-case technique [3] could be applied in Bahrain to strengthen the screening process.

\subsubsection{Scoping}

Scoping process ensures that all potential impacts are addressed in the EIA. The DEAP usually specifies the key environmental concerns of the projects as terms of reference. Scoping is conducted by the appointed consulting firm after a deliberation with the DEAP to overcome the possibilities of neglecting significant impacts. All of the interviewed EIA consultants agreed that this 
approach of scoping has the advantage of identifying all the significant impacts of the proposed projects.

Nonetheless, evidence is increasing that most adverse environmental effects may result not from the direct effects of a particular project, but from the combination and interaction of individually minor effects of multiple projects over time [21]. Scoping in Bahrain is typically conducted without investigating environmental impacts in relation to other similar existing or planned developpments. Therefore, cumulative impacts that may result from several projects might be completely neglected in the scoping process.

\subsubsection{Alternatives}

The consideration of alternatives is an integral part of EIA procedure that allows for a comprehensive approach to investigate the most appropriate design, process and location for a proposed project [3]. Investigating feasible site alternatives is generally limited in Bahrain as indicated by the majority of the EIA practitioners. Generally, most of the projects were in late stages of implementation and their sites were allocated or purchased by the project proponents upon before the EIA was commenced.

\subsubsection{Public Participation}

IAIA [22] defined public participation as the involvement of individuals or groups that are positively or negatively affected by a proposed project subject to decision making process. Public participation is influenced by social, cultural and political contexts within which the EIA takes place [23]. Limited public involvement in the EIA process is considered a key obstacle in achieving effective EIA in developing countries [19] and Bahrain is no exception. Currently, there are no legal requirements for public participation in EIA process in Bahrain. However, public interest in EIA has increased over time. Invitations are sent to local societies and non-governmental organizations to discuss environmental implications of major projects. Recently, public exhibitions showing environmental and health aspects of major projects are organized. For instance, public exhibition on a sanitary engineering project was held on April 2011. Most of the interviewed academics argued that public participation in the EIA process in Bahrain will increase the general environmental awareness. Consequently, perception among the public and the project proponents that EIA is an essential and integral part of environmental sustainability rather than mainly a legal obligation will increase.

\subsubsection{EIA Review and Decision Making}

EIA review ensures that information on environmental impacts of an action is adequate before it is used as a basis for decision making [16]. Reviewing the EIA reports is conducted by the DEAP within 60 days of sub- mission date. Like most of the countries of Western Asia [24], there is no formal procedure for reviewing the EIA reports in Bahrain. In practice, review is conducted by a committee in the DEAP that is typically composed of multidisciplinary technical staff. Ecologists, economists and engineers are members of the committee, which could aid the review process. DEAP may organize meetings with relevant stakeholders to exchange opinions and comments concerning major proposed projects, which contribute to the review process. However, $70 \%$ of the EIA practitioners interviewed indicated that external expert and public inputs in reviewing EIA process are limited. Some interviewed academics suggested that University of Bahrain could be involved as an independent review body to evaluate the quality of EIA reports in cooperation with the DEAP. The decision making of providing environmental license for a proposed project is the responsibility of the General Director of the GDPWE based on recommendation from the rearview committee at the DEAP.

\subsubsection{Mitigation and Monitoring}

Mitigation in EIA aims to avoid, minimize or compensate for significant adverse impacts [25]. Most of the interviewed environmental consultants indicated that mitigation measures are generally restricted to the physical characteristics of the projects. For instance, mitigation measures of dredging and reclamation involve only minimizing water turbidity within the local project area. Similarly, artificial reefs are typically proposed as a compensation measure to restore the damaged ecosystems affected by major projects associated with extensive dredging and reclamation activities. However, $50 \%$ of the EIA practitioners interviewed suggested that commitments to the proposed mitigation measures by project proponents are limited.

Environmental monitoring is an important process in examining the accuracy of the predicted impacts and their associated mitigation measures [25]. Monitoring requirements in Bahrain are generally part of the authorization conditions to be conducted by the project proponent. However, the Bahraini environmental laws only require the monitoring of air emissions and wastewater effluents of major industrial projects based on the Ministerial Order No. 10 of 1999 with respect to environmental standards (air and water) and its subsequent amendments. Major industrial projects are required to submit reports on a quarterly basis indicating the quality status of their emissions and/or effluents. Although measuring selected chemical components or elements may indicate the level of contaminants, this approach alone may not reflect the biological and ecological status as a result of environmental impacts [26]. Therefore, there is a need for a comprehensive concept of monitoring that comprises 
biological, physical and chemical aspects of the environment, as agreed by all of the EIA practitioners during the interviews.

\subsubsection{Experience of SEA}

Strategic Environmental Assessment (SEA) is recognized as an important decision support tool for integrating environmental concerns along with social and economic considerations into proposed policies, plans and programmes [4]. SEA has emerged as an important element in environmental decision-making process in developed countries, including Europe and North America, and is being introduced in several developing countries [27]. However, SEA has not been explicitly recognized or legally adopted as a mechanism to deliver high environmental policy objectives in Bahrain.

Bahrain, in cooperation with United Nations Development Programme (UNDP), launched the National Environmental Strategy (NES), which was approved by the Council of Ministers in 2006. The NES aims to implement the effective coordination and integration of environmental issues in development planning in Bahrain. The NES indentifies mechanisms by which principles of sustainable development can be implemented. These mechanisms include: enforcing the role of EIA during planning; implementation and after commissioning phases of major projects; adopting principles of integrated environmental management for coastal and marine environments; applying valuation systems to estimate the costs of environmental degradation and rehabilitation; strengthening institutional and legal frameworks; and increasing public awareness and participation. Although the NES could have implications that interlink with SEA principles, it lacks action plans for implementation that limits its enforcement.

\section{EIA Foundation Measure}

\subsection{EIA Guidelines}

Existence of EIA guidelines is considered as a foundational measure to improve the effectiveness of EIA system [16]. Several booklets indicating the general procedure of EIA have been produced by the Directorate of Public Relations and Environmental Media (DPREM). Similarly the DEAP produced brief guidelines concerning the topics to be covered in EIA reports. These guidelines are extended forms of the requirements stated in Articles 8 and 9 of the EIA Order. More comprehensive guidelines related to ecological surveys and monitoring suspended sediments of projects involving dredging and reclamation activities have been produced in 2006 by the DEAP. Shortcomings related to the quality of ecological input in 15 Bahraini EIA reports concerning coastal and marine developments produced between 1996 and 2004 were reported [28]. The existence of the recent guidelines has improved the quality of the EIA reports, as suggested by $60 \%$ of the EIA practitioners. However, all of them agreed that further guidelines addressing all aspects of the EIA process in Bahrain are critically required.

\subsection{Monitoring EIA System}

Follow-up and monitoring the performance of EIA are required to improve the effectiveness of EIA system [29]. These involve monitoring the compliance of predicted impacts and mitigation measures with the actual impacts of the completed and mitigated projects. Studies and reviews investigating the performance of EIA could be utilized to strengthen the effectiveness of the EIA process. The current study might be considered as an initial step in that direction.

\subsection{EIA Experts and Consultants}

Availability of expertise is critical to the effectiveness of EIA system [19]. Highly qualified experts in the EIA are employed by the GDPEW in Bahrain. However, it is recognized that these experts are limited in number and overloaded with work duties, as indicated by the majority of the EIA practitioners interviewed.

Academic institutes such as University of Bahrain and Arabian Gulf University possess highly qualified experts in several scientific fields related to the EIA. During the interviews, most experts stressed that further cooperation between their institutes and relevant governmental bodies in the field of EIA is needed.

There are several local, regional and international environmental consulting firms in Bahrain. These firms are registered in terms of Ministerial Order No. 3 of 2000 with respect to registering environmental consultants performing environmental assessment of projects and environmental studies. This Order was issued after a consultation with the Economic and Social Commission for Western Asia (ESCWA) of the United Nations [30]. According to this Order, consulting firms interested in conducting EIA studies and having the required capabilities, experience and manpower apply formally to the DEAP along with relevant documents and certificates based on which DEAP evaluates their capabilities and register them for conducting EIA in Bahrain. Most of the EIA practitioners agreed that this Order ensures high standards of environmental consultation process in Bahrain. A list of accredited environmental consultants working in Bahrain is maintained by the DEAP. Most of local environmental consultants are cooperating with established international firms in conducting EIA in Bahrain. The current practice of merging international experience of EIA with local environmental knowledge may improve the effectiveness of EIA in Bahrain, as agreed by most of 
the EIA practitioners.

\subsection{Training and Building Capacity}

Training and education in EIA contribute to capacity building [26]. Most of the EIA practitioners argued that facilitating environmental training and education, and promoting environmental awareness are critical requirements toward enhancing the effectiveness of the EIA process in Bahrain. Higher education institutes may contribute the capacity building. Toward this, a course in EIA was introduced at the Department of Biology, University of Bahrain in 2009. Ten students skilled with background knowledge related to EIA were graduated between 2009 and 2011. Such initiative should reflect positively in capacity building of the EIA system.

\section{Conclusions and Recommendations}

This study initially evaluated the practice of EIA in Bahrain. Almost fifteen years after its implementation, EIA is increasingly contributing to the overall environmental policy objectives and promoting the principles of sustainable development in Bahrain. However, there are challenges facing an effective EIA process in Bahrain. Legislative amendments to composite the whole aspects of EIA process, including public participations, cumulative impacts, alternatives and provisions for SEA will strengthen the EIA system in Bahrain. Guidelines on procedural EIA, including screening, scoping, review, impact assessment, mitigation and monitoring will improve the quality of EIA. Importance and benefits of EIA are required to be sufficiently introduced among public, which will increase public environmental awareness and participation in the EIA process. Providing better access to EIA related documents could enhance public involvement in EIA process in Bahrain.

Environmental monitoring is required to strengthen the commitment of project proponents to mitigation measures. Additionally, a comprehensive approach of monitoring that involves biological, physical and chemical aspects of the environment should be introduced. This should not be limited to individual projects, but extended to monitor cumulative or synergistic impacts of several projects.

Action plans for the NES to incorporate EIA and environmental sustainability principles into various governmental bodies and relevant stakeholders in Bahrain are critically required. It is important to implement EIA process at early stages of project life cycle. This could be achieved by integrating environmental concerns to higherlevel policy making and strengthening the mandate of PCPMREW to be responsible of coordinating environmental concerns and activities among all governmental and private sectors in Bahrain. While efforts are being made to enhance the capacity building of EIA in Bahrain, sharing EIA-related knowledge between academic institutions and decision makers could enhance the EIA process. Findings of this study revealed that constraints of effective EIA in Bahrain are also prevalent in many developing countries in the world.

\section{Acknowledgements}

Thanks are due to Prof. Jameel Al-Khuzai, Dr. Hashim Al-Sayed and Dr. Khadija Zainal from the Department of Biology, College of Science, University of Bahrain for their constructive comments. The contributions by the EIA practitioners are highly appreciated.

\section{REFERENCES}

[1] J. Glasson, R. Therivel and A. Chadwick, "Introduction to Environmental Impact Assessment,” Spon Press, London, 2005.

[2] International Association of Impact Assessment, "Principles of Environmental Impact Assessment Best Practice,” IAIA, Johannesburg, 1999.

[3] B. Noble, "Introduction to Environmental Impact Assessment: A Guide to Principles and Practice,” Oxford University Press, Oxford, 2010.

[4] H. Alshuwaikhat, "Strategic Environmental Assessment Can Help Solve Environmental Impact Assessment Failures in Developing Countries," Environmental Impact Assessment Review, Vol. 25, No. 4, 2005, pp. 307-317. doi:10.1016/j.eiar.2004.09.003

[5] B. Ahmed and C. Wood, "A Comparative Evaluation of the EIA Systems in Egypt, Turkey and Tunisia," Environmental Impact Assessment Review, Vol. 22, No. 3, 2002, pp. 213-234. doi:10.1016/S0195-9255(02)00004-5

[6] K. El-Fadl and M. El-Fadel, "Comparative Assessment of EIA Systems in MENA Countries: Challenges and Prospects," Environmental Impact Assessment Review, Vol. 24, No. 6, 2004, pp. 553-593. doi:10.1016/j.eiar.2004.01.004

[7] T. Ramjeawon and R. Beedassy' "Evaluation of the EIA System on the Island of Mauritius and Development of an Environmental Monitoring Framework,” Environmental Impact Assessment Review, Vol. 24, No. 5, 2004, pp. 537549. doi:10.1016/j.eiar.2004.01.001

[8] T. Zeremariam and N. Quinn, "An Evaluation of Environmental Impact Assessment in Eritrea," Impact Assessment and Project Appraisal, Vol. 25, No. 1, 2007, pp. 53-63. doi:10.3152/146155107X190604

[9] E. Badr, "Evaluation of the Environmental Impact Assessment System in Egypt," Impact Assessment and Project Appraisal, Vol. 27, No. 3, 2009, pp. 193-203. doi:10.3152/146155109X465959

[10] F. Haydar and K. Pediaditi, "Evaluation of the Environmental Impact Assessment System in Syria," Environmental Impact Assessment Review, Vol. 30, No. 6, 2010, pp. 363-370. doi:10.1016/j.eiar.2009.11.003 
[11] J. Toro, I. Requena and M. Zamorano, "Environmental Impact Assessment in Colombia: Critical Analysis and Proposals for Improvement," Environmental Impact Assessment Review, Vol. 30, No. 4, 2010, pp. 247-261. doi:10.1016/j.eiar.2009.09.001

[12] B. Sadler and R. Verheem, "Strategic EIA: Status, Challenges and Future Directions,” World Bank, Washington, 1996.

[13] J. O’Brien, R. Keivani and J. Glasson, “Towards a New Paradigm in Environmental Policy Development in HighIncome Developing Countries: The Case of Abu Dhabi, United Arab Emirates,” Progress in Planning, Vol. 68, No. 4, 2007, pp. 201-256. doi:10.1016/j.progress.2007.09.001

[14] C. Wood, "Comparative Evaluation of Environmental Impact Assessment Systems,” In: J. Petts, Ed., Handbook of Environmental Impact Assessment: Environmental Impact Assessment in Practice: Impacts and Limitations, Blackwell, London, 1999, pp. 10-34.

[15] O. Nadeen and R. Hameed, "Evaluation of Environmental Impact Assessment System in Pakistan,” Environmental Impact Assessment Review, Vol. 28, No. 8, 2008, pp. 562-571. doi:10.1016/j.eiar.2008.02.003

[16] K. Fuller, "Quality and Quality Control in Environmental Impact Assessment,” In: J. Petts, Ed., Handbook of Environmental Impact Assessment: Environmental Impact Assessment in Practice: Impacts and Limitations, Blackwell, London, 1999, pp. 55-82.

[17] H. Naser, "Human Impacts on Marine Biodiversity: Macrobenthos in Bahrain, Arabian Gulf,” In: J. LopezPujol, Ed., The Importance of Biological Interactions in the Study of Biodiversity, InTech Publishing, Midlothian, 2011, pp. 109-126.

[18] J. Glasson and N. Salvador, "EIA in Brazil: A Procedures-Practice Gab. A comparative Study with Reference to European Union, and Especially the UK,” Environmental Impact Assessment Review, Vol. 20, No. 2, 2000, pp. 191225. doi:10.1016/S0195-9255(99)00043-8

[19] C. Wood, "Environmental Impact Assessment in Developing Countries,” International Development Planning Review, Vol. 25, No. 3, 2003, pp. 301-321. doi:10.3828/idpr.25.3.5
[20] Kingdom of Bahrain, "National Report to the World Summit on Sustainable Development. Bahrain,” Ministry of State for Municipalities Affairs and Environmental Affairs, Bahrain, 2002.

[21] Z. Ma, D. Becker and M. Kilgore, “Assessing Cumulative Impacts within State Environmental Review Frameworks in the United States," Environmental Impact Assessment Review, Vol. 29, No. 6, 2009, pp. 390-398. doi:10.1016/j.eiar.2009.03.004

[22] International Association of Impact Assessment, "Public Participation Best Practice Principles,” IAIA, Midlothian, 2006.

[23] H. Abaza, "Strengthening Future Environmental Assessment Practice: and International Perspective,” In: N. Lee and C. George, Eds., Environmental Assessment in Developing Countries: Principles, Methods and Practice, Wiely, Hoboken, 2000, pp.271-282.

[24] UNESCWA, “A Study on the Evaluation of Environmental Impact Assessment in Selected ESCWA Countries," Economic and Social Commission for Western Asia, United Nations, New York, 2001.

[25] J. Treweek, “Ecological Impact Assessment,” Blackwell, Oxford, 1999.

[26] H. Naser, “Using Macrobenthos as a Tool in Ecological Assessment: Application in Environmental Impact Assessment (EIA)," Lambert Academic Publishing, Saarbrucken, 2010.

[27] T. Fischer, "Theory and Practice of Strategic Environmental Assessment: Toward a More Systematic Approach,” Earthscan, London, 2007.

[28] H. Naser, J. Bythell and J. Thomason, "Ecological Assessment: An Initial Evaluation of the Ecological Input in Environmental Impact Assessment Reports in Bahrain,” Impact Assessment and Project Appraisal, Vol. 26, No. 3, 2008, pp. 201-208. doi:10.3152/146155108X333271

[29] J. Arts, “Assessing Impacts: Handbook of EIA and SEA Follow-Up,” Earthscan, London, 2004.

[30] H. Khordagui, "Suggested Methodology for the Selection of Environmental Impact Assessment Consulting Firms for the State of Bahrain,” United Nations, Economic and Social Commission for Western Asia, Beirut, 2000. 